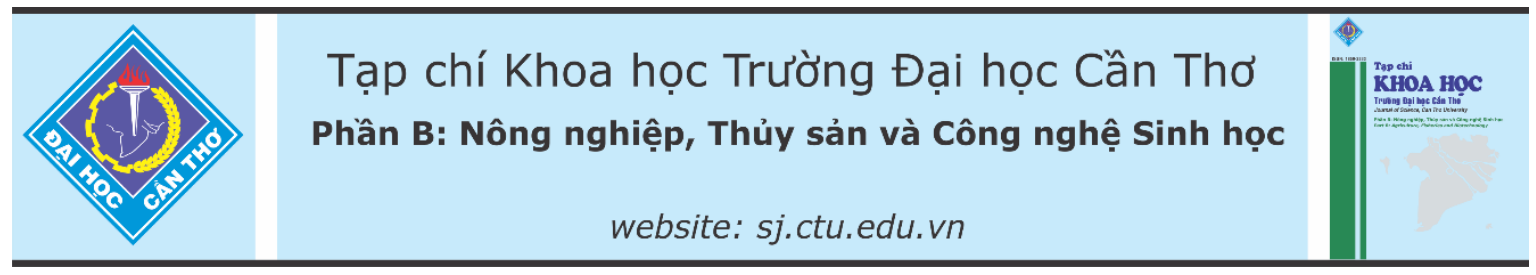

DOI:10.22144/ctu.jvn.2021.043

\title{
GIẢM THIỂU TÁC HẠI MÔI TRƯờnG VÀ TĂNG THU NHẬP THÔNG QUA ÁP DỤNG MÔ HÌNH CANH TÁC LÚA-CÁ-CÂY ÂN TRÁI KẾT HỘP Ở AN GIANG
}

\author{
Cao Quốc Nam ${ }^{1 *}$, Phạm Văn Trọng Tính ${ }^{1}$, Nguyễn Thành Trực ${ }^{1}$, Châu Quốc Mộng ${ }^{1}$, \\ Nguyễn Hữu An Khương ${ }^{2}$ và Nguyễn Duy Cần ${ }^{1}$ \\ ${ }^{1}$ Khoa Phát triển Nông thôn, Trường Đại học Cần Tho \\ ${ }^{2}$ Công ty Cổ phần Tập đoàn Lộc Trời, chi nhánh nhà máy sản xuất hạt giống Định Thành \\ *Người chịu trách nhiệm về bài viết: Cao Quốc Nam (email: cqnam@ctu.edu.vn)
}

\section{Thông tin chung:}

Ngày nhận bài: 22/10/2020

Ngày nhận bài sưa: 25/01/2021

Ngày duyệt đăng: 28/04/2021

\section{Title:}

Reducing enviromental damages and increasing incomes through applying integrated rice-fish-fruit systems in An Giang

\section{Tù khóa:}

Lúa độc canh, lợi nhuận, mô hình lúa-cá-cây ăn trái, thuốc bảo vệ thưc vật, VietGAP

\section{Keywords:}

Mono rice system, profit, ricefish-fruit systems, pesticides, VietGAP

\begin{abstract}
This study is conducted to evaluate the feasibility of the rice-fish-fruit integrated systems, the reduction of toxic pesticides use, the increasing income and producing of rice and fish VietGAPs. The experiment of rice-fishfruit integrated systems was carried out in 3 farmer's fields to compared with mono rice farming systems at An Giang province. By applying the intercropping of 2 rice crops - 1 fish crop, the rice and fish products were achieved VietGAP standards and certified. The toxic pesticides used for rice production in the rice-fish-fruit systems were lower than that for mono rice systems, at $28 \%$ and $39 \%$ respectively. Due to the additional income from fruit and higher net return from rice, the total returns and net incomes of the rice-fish-fruit systems tended to be higher than those of mono rice systems, 53\% and 209\% respectively. The fish production in this study did not bring extra profit due to low survival rate of some fish species and low market price of pangasius catfish. For further improvement of the profitability and profit margin of the rice-fish-fruit systems, it is proposed that the research should focus on increasing the market price of VietGAP rice and fish products as well as improving fish yield.
\end{abstract}

\section{TÓM TẮT}

Nghiên cúu thực hiện nhằm đánh giá tính khả thi của mô hình lúa-cá-cây ăn trái, sụ giảm sử dụng thuốc bảo vệ thực vật độc hại, sụ tăng thu nhập và tạo sản phẩn lúa-cá VietGAP. Thí nghiệm được bố trí trên 3 ruộng nông dân và so sánh với mô hình của nông dân lúa độc canh tại tỉnh An Giang. Bằng hình thức xen canh 2 vu lúa - 1 vu cá, sản phẩm lúa và cá đạt chứng nhận VietGAP. Thuốc bảo vệ thực vật sủ dụng cho lúa có độ độc cao (nhóm độc II) ở mô hình lúa-cá-cây ăn trái là $28 \%$ thấp hơn so với ở mô hình lúa độc canh (39\%). Do có nguồn thu thêm tù cây ăn trái và lợi nhuận tù lúa cao hơn nên tổng thu và lợi nhuận của mô hình lúa-cá-cây ăn trái cao hơn lần lươt 53\% và 209\% so với ở mô hình lúa độc canh. Cá nuôi trong nghiên cứu này chura mang lại lợ nhuận do tỷ lệ sống của một số loài thấp và giá bán cá tra giảm thấp. Cần tiếp tuc nghiên cứu nâng giá bán lúa và cá đã đạt chứng nhận VietGAP và cải tiến năng suất cá để nâng cao hơn nữa lợi nhuận và tỷ suất lợi nhuận của mô hình lúa-cá-cây ăn trái.

\section{GIỚI THIỆU}

Từ những năm của thập niên 1990, thâm canh tăng vụ trong sản xuất lúa ở khu vực Đồng bằng sông Cửu Long (ĐBSCL) nói chung và ở tỉnh An Giang nói riêng đã được áp dụng (Nguyễn Quang Tuyến, 2013). Bên cạnh mặt tích cực là tăng năng 
suất và sản lượng lúa, thâm canh tăng vụ buộc nông dân phải tăng lượng phân bón và thuốc bảo vệ thực vật (BVTV). Nhiều nghiên cứu cho thấy việc sử dụng quá mức thuốc BVTV trên lúa sẽ tác động xấu đến môi trường và ảnh hưởng bất lợi đến sản xuất lúa bền vững ở Việt Nam (Berg, 2002; Phạm Văn Toàn, 2013; United Nations Environment Program, 2005). Trong bối cảnh đó, để sản xuất lúa theo hướng an toàn và bền vững nhiều kỹ thuật canh tác đã được nghiên cứu và triển khai: phòng trừ dịch hại tổng hợp (IPM), xen canh lúa-cá, canh tác theo hướng sinh thái,... (Berg, 2002; Garbach et al., 2014; Phạm Văn Toàn, 2013).

Theo quy hoạch phát triển nông nghiệp tỉnh An Giang đến năm 2020 và định hướng đến năm 2030, sản xuất lúa theo hướng hình thành các vùng chuyên canh lúa hàng hóa chất lượng cao, có quy trình sản xuất theo hướng GAP, gắn kết với các hoạt động du lịch, ... để nâng cao thu nhập và hướng đến canh tác lúa bền vững (Sở Nông nghiệp và Phát triển nông thôn tỉnh An Giang, 2014). Xã Ô Long Vĩ là một xã nghèo của huyện Châu Phú, tỉnh An Giang, người dân chủ yếu canh tác 2-3 vụ lúa/năm. Thời gian qua ngành BVTV của địa phương đã triển khai một số kỹ thuật sản xuất lúa theo hướng an toàn: "1 phải 5 giảm", trồng hoa trên bờ ruộng, nuôi nấm xanh trừ rầy nâu,... Mặc dù vậy, việc sử dụng thuốc BVTV trong canh tác lúa vẫn không giảm. Trong các kỹ thuật sản xuất nêu trên, trên địa bàn xã Ô Long Vĩ đang có một số hộ nông dân áp dụng mô hình xen canh lúa-cá-cây ăn trái. Đây là mô hình được xem là rất có triển vọng trong việc kiểm soát dịch hại trên lúa, giảm sử dụng thuốc BVTV và tăng thu nhập (Berg, 2002; Halwart \& Gupta, 2004; Lê Thị Thanh Nga \& Lê Xuân Sinh, 2008). Tuy nhiên, cho đến nay mô hình canh tác kết hợp này vẫn chưa được nghiên cứu và đánh giá. Vì vậy vấn đề đặt ra của nghiên cứu này là nhằm đánh giá tính khả thi của mô hình lúacá-cây ăn trái kết hợp tác động đến việc giảm sử dụng thuốc bảo vệ thực vật độc hại, gia tăng thu nhập và tạo được sản phẩn lúa-cá VietGAP.

\section{PHƯƠNG PHÁP NGHIÊN CÚU}

\section{1. Địa điểm và thời gian nghiên cứu}

Nghiên cứu thực hiện tại xã Ô Long Vĩ, huyện Châu Phú, tỉnh An Giang, nơi đây áp dụng mô hình độc canh 3 vụ lúa/năm trong vùng có đê bao hoàn chỉnh, chính quyền và người dân mong muốn phát triển mô hình sản xuất lúa theo hướng VietGAP có kết hợp với nuôi cá và trồng cây ăn trái. Nghiên cứu được thực hiện từ tháng 7/2017 đến tháng 11/2019 bao gồm 02 vụ nuôi cá trên ruộng, số liệu của vụ xen canh lúa-cá thứ 2 , từ tháng $8 / 2018$ đến tháng $11 / 2019$.

\subsection{Bố trí thí nghiệm}

\subsubsection{Chọn nông dân thực hiện thí nghiệm}

Ba hộ nông dân được chọn để xây dựng mô hình thử nghiệm kết hợp lúa-cá-cây ăn trái (L-C-CAT) có các tiêu chí sau: 0,78 ha - 1 ha/ruộng, nông dân sẵn sàng hợp tác trên cơ sở tự nguyện và cùng quan tâm. Ngoài ra, 03 hộ độc canh 3 vụ lúa/năm (lúa ĐC) theo kỹ thuật phổ biến của địa phương được chọn làm nhóm đối chứng. Nông dân trong nhóm chọn làm đối chứng có điều kiện canh tác, diện tích ruộng, kinh nghiệm sản xuất lúa và có năng suất lúa tương tự như các hộ tham gia thử nghiệm ở các vụ canh tác trước.

\subsubsection{Bố trí thí nghiệm}

Nghiên cứu sử dụng phương pháp tiếp cận "Phát triển kỹ thuật có sự tham gia" (Participatory technology development - PTD), thí nghiệm thực hiện trên ruộng của nông dân, do nông dân thực hiện và quản lý theo điều kiện của họ (Laurens et al., 1997; Nguyễn Duy Cần và ctv., 2009) Trong nghiên cứu này, mô hình thử nghiệm L-C-CAT được thực hiện trên 3 ruộng, có diện tích từ 0,78 ha đến 1,31 ha/ruộng, gồm có bờ bao (15-25\%), mương (10$20 \%$ ) và phần còn lại là ruộng lúa. Bờ bao xung quanh ruộng, cao hơn mực nước trong ruộng ít nhất $0,80 \mathrm{~m}$. Cây ăn trái được trồng trên bờ vào cuối năm 2017 (Bảng 1). Mương bao dạng chu vi, bao quanh ruộng, sâu 1,2 - 1,5 m. Ruộng có mặt bằng tương đối, trên ruộng được đánh nhiều đường rãnh để dễ thoát nước và cho cá lên xuống ruộng.

Bảng 1. Số lượng chủng loại cây ăn trái trồng trên bờ bao của mô hình lúa-cá-cây ăn trái

\begin{tabular}{|c|c|c|c|c|c|c|c|c|c|}
\hline $\begin{array}{l}\text { Nông } \\
\text { dân }{ }^{(*)}\end{array}$ & $\begin{array}{l}\text { Cam } \\
\text { sành }\end{array}$ & $\begin{array}{c}\begin{array}{c}\text { Bưởi da } \\
\text { xanh Mít }\end{array} \\
\end{array}$ & Thái & $\begin{array}{r}\text { Xoài } \\
\text { keo }\end{array}$ & $\begin{array}{r}\text { Chanh } \\
\text { giấy }\end{array}$ & Ồi & $\begin{array}{r}\text { Cà na } \\
\text { Thái }\end{array}$ & cầu & Dừa \\
\hline 1 & 30 & 120 & 60 & 0 & 0 & 40 & 23 & 70 & $\overline{0}$ \\
\hline 2 & 0 & 23 & 0 & 213 & 145 & 0 & 0 & 0 & 22 \\
\hline 3 & 60 & 380 & 325 & 0 & 0 & 0 & 0 & 0 & 30 \\
\hline
\end{tabular}

${ }^{(*)}$ Nông dân 1: 20 cây buơoi da xanh và 60 cây mít Thái trồng ở năm 2016; Nông dân 2: 213 cây xoài keo và 145 cây chanh giấy trồng ở năm 2016; và Nông dân 3: 25 cây mít Thái trồng ở năm 2016. 
Trong canh tác lúa, sử dụng giống chất lượng cao, phù hợp với địa phương (Đài Thơm 8 và Jasmine 85 ) và áp dụng phương pháp sạ lan. Phân bón và thuốc $\mathrm{BVTV}$ sử dụng theo hướng canh tác VietGAP, nằm trong danh mục cho phép của $B$ ộ Nông nghiệp và Phát triển Nông thôn hiện hành. Quản lý dịch hại áp dụng theo biện pháp IPM, ưu tiên sử dụng các chế phẩm sinh học, thuốc BVTV có nhãn màu xanh trước khi sử dụng thuốc hóa học khác khi có dịch bệnh xãy ra. Để cá dễ dàng vào ruộng, mực nước trên ruộng được khuyến khích ở mức $5-15 \mathrm{~cm}$ từ 10 ngày sau khi sạ (NSKS) đến trước khi thu hoạch lúa một tuần.

Sau khi đào mương và đắp bờ, vôi nông nghiệp được bón xuống mương và bờ bao (10-15 kg/100 $\mathrm{m}^{2}$ ). Trước khi thả cá 10 ngày, cá tạp và cá dữ được diệt bằng dây thuốc cá $\left(15 \mathrm{~g} / \mathrm{m}^{3}\right.$ nước $)$. Với mục tiêu nuôi cá đồng có khả năng hạn chế sâu rầy, có giá trị cao và nuôi theo hướng đạt chuẩn VietGAP, số loài cá và mật độ thả của các loài cá trong ruộng thử nghiệm được trình bày ở Bảng 2 . Cá được thả vào ruộng lúc 20-25 NSKS lúa vụ Thu Đông (9/2018) và thu hoạch sau vụ lúa Đông Xuân 2018-2019 khoảng 15 ngày (4/2019). Tuy nhiên ở ruộng nông dân 3 (ND3), do ảnh hưởng từ nước mưa, việc nâng cấp hệ thống tưới, thoát nước trên bờ trồng bưởi nên sau khi thả cá khoảng 45 ngày nước trong ruộng bị nhiễm phèm nặng $(\mathrm{pH}$ nước $<4,5)$ trong nhiều ngày (tháng 10-11/2019) làm cho cá nuôi chết gần hêt. Đến gần cuối vụ Đông Xuân 2018-2019, ruộng ND3 được cả tạo lại và thả mới cá giống vào đầu tháng 4/2019. Cá được nuôi qua vụ Hè Thu 2019 và thu hoạch vào gần cuối vụ Thu Đông 2019 (11/2019). Ở ruộng ND1 và ND2, thức ăn công nghiệp có hàm lượng đạm 26-30\% được bổ sung cho cá với lượng $2-5 \%$ trọng lượng đàn cá tra. Hàng tuần men vi sinh, vitamin $\mathrm{C}$ được trộn vào thức ăn cho cá và không có sử dụng thuốc kháng sinh. Ruộng ND3 không có bổ sung thức ăn, cá chỉ ăn thức ăn tự nhiên.

Bảng 2. Mật độ thả (con/ha), cỡ thả (g/con) và tỷ lệ (\%) của các loài cá tại 03 ruộng thí nghiệm

\begin{tabular}{lrrrrrrrrr}
\hline \multirow{2}{*}{ Loài cá } & \multicolumn{3}{c}{ Nông dân 1 } & \multicolumn{4}{c}{ Nông dân 2 } & \multicolumn{3}{c}{ Nông dân 3 } \\
\cline { 2 - 10 } & con/ha & g/con & \% & con/ha & g/con & \% & con/ha & g/con & \% \\
\hline Rô đồng & 2.762 & 5,5 & 61,3 & 2.712 & 6,5 & 66,0 & 2.500 & 4,0 & 45,3 \\
Sặc rằn & - & - & - & - & - & - & 2.500 & 5,6 & 45,3 \\
Trê vàng & - & - & - & - & - & - & 513 & 18 & 9,3 \\
Tra & 1.746 & 66,7 & 38,7 & 1.396 & 38,0 & 34,0 & - & - & - \\
\hline Tổng cộng & 4.508 & - & 100 & 4.108 & - & 100 & 5.513 & - & 100 \\
\hline
\end{tabular}

\subsubsection{Các chỉ tiêu theo dõi và phân tích số liệu}

Trước khi thu hoạch lúa 03 ngày, năng suất lúa thực tế được xác định bằng cách thu mẫu 3 điểm ngẫu nhiên trên ruộng $\left(5 \mathrm{~m}^{2} /\right.$ điểm), tính ở ẩm độ chuẩn $14 \%$. Đối với cá, thu các chỉ tiêu: (1) tỷ lệ sống [(số cá thu/số cá thả) x100], (2) tốc độ tăng trưởng, $\mathrm{g} /$ ngày $\{[$ lượng thu $(\mathrm{g} / \mathrm{con})$ - lượng thả (g/con)]/thời gian nuôi\}, (3) năng suất thu hoạch (lượng cá thu, $\mathrm{kg} / \mathrm{ha}$ ) và (4) năng suất thuần [lượng cá thu $(\mathrm{kg} / \mathrm{ha})$ - lượng cá thả $(\mathrm{kg} / \mathrm{ha})]$. Tổng chi phí sản xuất lúa, cá và cây ăn trái gồm chi phí cố định và biến đổi. Chi phí cố định của cá và cây ăn trái gồm chi phí xây dựng bờ bao, mương, lưới, cây giống, dụng cụ, bao bì (đã tính theo khấu hao). Riêng ở lúa, chi phí cố định giả sử giống nhau giữa hai mô hình và không đưa vào tổng chi phí sản xuất lúa. Chi phí biến đổi gồm: (1) lúa: giống, phân, thuốc BVTV, thuê máy làm đất, thuê bơm nước, thuê thu hoạch lúa, lao động chuẩn bị ruộng và chăm sóc lúa (lao động nhà và lao động thuê); (2) cá: cá giống, dây thuốc cá, vôi, thức ăn, bơm nước và lao động (nhà và thuê); và (3) cây ăn trái: phân, thuốc BVTV, bơm tưới và lao động (nhà và thuê). Ở trường hợp cây ăn trái, trong chi phí biến đổi có cộng thêm chi phí biến đồi của 02 năm đầu chưa thu hoạch trái (đã tính theo khấu hao), với giả định năm thứ 3 cây bắt đầu cho trái đến năm thứ 6 . Đối với hiệu quả tài chính của từng hợp phần lúa, cá và cây ăn trái trong mô hình L-C-CAT được hạch toán tài chính từng hợp phần. Đối với hiệu quả tài chính của hai mô hình canh tác L-C-CAT và lúa $\mathrm{ĐC}$, hạch toán tài chính toàn phần được áp dụng. Trong đó, mô hình L-C-CAT có ba hợp phần là lúa, cá và cây ăn trái. Mô hình lúa $Đ C$ chỉ có hợp phần lúa. Tổng chi phí và lợi nhuận được tính: (1) Tổng chi phí $=$ chi phí cố định + chi phí biến đồi; (2) Tổng thu = sản lượng $\mathrm{x}$ giá bán; (3) Lợi nhuận = tổng thu - tổng chi phí; (4) Thu nhập = Lợi nhuận + Chi phí lao động gia đình; và (5) Tỷ suất lợi nhuận trên chi phí hay tổng thu = lợi nhuận/tổng chi phí hay tổng thu.

Tỷ suất của lợi nhuận biên tế được tính toán để đánh giá hiệu quả của các mô hình L-C-CAT (mô hình mới) và lúa $\mathrm{C}$ (mô hình cũ, phổ biến) bằng cách sử dụng phương pháp của Trung tâm cải tiến ngô và lúa mì quốc tế (The International Maize and Wheat Improvement Center [CIMMYT], 1988), tỷ 
suất của lợi nhuận biên tế (marginal rate of return MRR $), M R R=[($ Lợi nhuận biên tế/Chi phí biên tế) $\mathrm{x}$ 100]. Trong đó: lợi nhuận biên tế là phần gia tăng lợi nhuận và chi phí biên tế là phần tăng thêm chi phí khi thay đổi từ mô hình đầu tư ít (lúa $\mathrm{C}$, mô hình cũ) sang mô hình đầu tư nhiều hơn (L-C-CAT, mô hình mới). Khi giá trị MRR đạt $\geq 50 \%$, thì mô hình mới đã mang lại lợi nhuận, có thể chấp nhận cho sản xuất (CIMMYT, 1988). Bên cạnh đó, phương pháp phân tích tài chính từng phần (partial budget analysis - PBA) cũng được sử dụng khi có sự thay thế kỹ thuật trong sản xuất nông nghiệp (Billy et al., 1991; Robert, 2018). Chỉ tiêu lợi nhuận (Tổng thu - Chi phí) được so sánh giữa mô hình L-C-CAT và lúa ĐC để đánh giá sự thay đổi giá trị trong phân tích tài chính từng phần $(\mathrm{PBA})$. Bảng 3 mô tả cách tính các thay đổi từng phần trong hai mô hình $\mathrm{L}-\mathrm{C}$ CAT và lúa ĐC. Qua so sánh: $\mathrm{III}=\mathrm{I}-\mathrm{II}$, nếu $\mathrm{III}>0$ nghĩa là mô hình L-C-CAT có hiệu quả tài chính; III $<0$ nghĩa là mô hình L-C-CAT không có hiệu quả tài chính so với mô hình lúa ĐC.

Phân tích thống kê mô tả được sử dụng để mô tả lượng đầu tư, năng suất lúa, các chỉ tiêu năng suất cá và cây ăn trái. Phương pháp so sánh trung bình 2 tổng thể độc lập T-Test được sử dụng để so sánh các chỉ số về kỹ thuật canh tác lúa, chi phí, tổng thu và lợi nhuận giữa mô hình $\mathrm{L}-\mathrm{C}-\mathrm{CAT}$ và lúa $\mathrm{ĐC}$. Ở một số trường hợp, số liệu đã được chuyển sang dạng $\log _{10}$ hay căn bậc hai để thỏa mãn các giả định trong phân tích T-Test. Khi các giả định trong phân tích
T-Test không được thỏa mãn, kiểm định phi tham số (Mann - Whitney) được áp dụng. Phần mềm thống kê SPSS 22,0 được sử dụng phân tích T-Test ở mức ý nghĩa $p \leq 0,05$.

\section{KÊT QUẢ VÀ THẢO LUẬN}

\subsection{Kỹ thuật canh tác và năng suất lúa}

\subsubsection{Lương giống và phân bón sư dụng trong canh tác lúa}

Lượng lúa giống và phân bón sử dụng cho lúa ở mô hình L-C-CAT và lúa ĐC ở 3 vụ lúa Thu Đông 2018 (3 ruộng thử nghiệm/mô hình), Đông Xuân 2018-2019 (2 ruộng thử nghiệm/mô hình) và Hè Thu 2019 (1 ruộng thử nghiệm/mô hình) được trình bày ở Bảng 4. Do ở vụ Đông Xuân 2018 - 2019, lượng cá trong ruộng của ND3 còn rất ít và được cải tạo thả cá mới nên số liệu lúa ở vụ này không ghi nhận ở hộ ND3 cũng như hộ đối chứng của ND3. Thay vào đó, số liệu lúa ở vụ Hè Thu 2019 được ghi nhận. Mặc dù nông dân ở mô hình L-C-CAT được khuyến cáo giảm lượng lúa giống và phân bón nhưng kết quả phân tích cho thấy lượng lúa giống và phân sử dụng cho lúa không khác biệt có ý nghĩa $(\mathrm{p}>0,05)$ giữa mô hình $\mathrm{L}-\mathrm{C}-\mathrm{CAT}$ và lúa ĐC canh. Tuy nhiên, nếu xét ở mức ý nghĩa $\alpha \leq 10 \%$ thì lượng phân đạm ở mô hình L-C-CAT ở vụ lúa Đông Xuân (123,5 kg N/ha) thấp hơn so với ở mô hình lúa ĐC (154,9 kg N/ha). Bên cạnh đó, lượng lúa giống áp dụng trong mô hình L-C-CAT cũng có xu hướng giảm xuống so với mô hình lúa ĐC.

\section{Bảng 3. Phân tích tài chính từng phần (PBA) để tính hiệu quả theo lợi nhuận}

\begin{tabular}{|c|c|}
\hline I: Phần tăng & II: Phần giảm \\
\hline $\mathrm{I}_{1}$ : Tồng thu tăng & $\mathrm{II}_{1}$ : Tổng thu giảm \\
\hline (Số tiền bán sản phẩm từ mô hình L-C-CAT) & (Số tiền bán sản phẩm từ mô hình lúa ĐC) \\
\hline $\mathrm{I}_{2}$ : Chi phí giảm & $\mathrm{II}_{2}$ : Chi phí tăng \\
\hline (Chi phí sản xuất trong mô hình lúa ĐC) & (Chi phí sản xuất trong mô hình L-C-CAT) \\
\hline Cộng $I=I_{1}+I_{2}$ & Cộng II $=\mathrm{II}_{1}+\mathrm{II}_{2}$ \\
\hline \multicolumn{2}{|l|}{ III: So sánh (III = I - II) } \\
\hline \multicolumn{2}{|c|}{ (III > 0: nên áp dụng mô hình L-C-CAT; III < 0: không nên áp dụng mô hình L-C-CAT) } \\
\hline
\end{tabular}

Theo Nguyễn Ngọc Đệ (2009), trên hầu hết các loại đất phù sa ở khu vực ĐBSCL, công thức phân $90-40-30\left(\mathrm{~kg} \mathrm{~N}, \mathrm{P}_{2} \mathrm{O}_{5}, \mathrm{~K}_{2} \mathrm{O} / \mathrm{ha}\right)$ có thể xem như mức khuyến cáo tổng quát cho đa số các giống lúa ngắn ngày. Trong khi đó, theo Lê Văn Dang và ctv. (2018), ở ĐBSCL phân đạm được khuyến cáo sử dụng khoảng 100-120 kg N/ha trong vụ Đông xuân và $80-100 \mathrm{~kg} \mathrm{~N} / \mathrm{ha}$ trong vụ Hè Thu. Phân lân được khuyến cáo $60-80 \mathrm{~kg} / \mathrm{P}_{2} \mathrm{O}_{5} /$ ha và kali được khuyến cáo ờ lượng 30-50 $\mathrm{kgK}_{2} \mathrm{O} / \mathrm{ha}$. Do vậy trong nghiên cứu này, ở cả các vụ lượng đạm được nông dân sử dụng có thể cao hơn mức khuyến cáo, cần giảm trong các vụ canh tác lúa kế tiếp. 
Bảng 4. Lượng lúa giống, phân bón và năng suất lúa thực tế trong hai mô hình canh tác ở các vụ lúa Thu Đông, Đông Xuân và Hè Thu ${ }^{(*)}$

\begin{tabular}{lrrr}
\hline Chỉ tiêu & L-C-CAT & Lúa ĐC & p $^{(* *)}$ \\
\hline Thu Đông 2018 & & & \\
\hline Giống (kg/ha) & $153,3 \pm 20,8$ & $187,3 \pm 29,2$ & 0,177 \\
Đạm (kg N/ha) & $132,2 \pm 19,2$ & $141,3 \pm 24,9$ & 0,643 \\
Lần (kg P/ha) & $56,5 \pm 12,4$ & $46,4 \pm 1,9$ & 0,237 \\
Kali (kg K/ha) & $50,7 \pm 5,0$ & $41,6 \pm 21,5$ & 0,519 \\
\hline Đông Xuân 2018-2019 & & & \\
\hline Giống (kg/ha) & $145,0 \pm 21,2$ & $176,9 \pm 32,7$ & 0,383 \\
Đạm (kg N/ha) & $123,5 \pm 9,5$ & $154,9 \pm 10,4$ & 0,088 \\
Lân (kg P/ha) & $58,2 \pm 20,3$ & $53,5 \pm 11,6$ & 0,812 \\
Kali (kg K/ha) & $50,2 \pm 8,8$ & $51,5 \pm 19,3$ & 0,942 \\
\hline Hè Thu 2019 & & & \\
\hline Giống (kg/ha) & 170,0 & 170,0 & - \\
Đạm (kg N/ha) & 139,0 & 153,0 & - \\
Lần (kg P/ha) & 57,0 & 50,0 & - \\
Kali (kg K/ha) & 47,0 & 72,0 & - \\
\hline Năng suất lúa (tấn/ha) & & & \\
\hline Thu Đông 2018 & $5,81 \pm 0,65$ & $4,87 \pm 1,14$ & 0,281 \\
Đông Xuân 2018-2019 & $5,83 \pm 0,14$ & $5,60 \pm 0,01$ & 0,260 \\
Hè Thu 2019 & 4,74 & 4,65 & - \\
Trung bình/vụ & $5,64 \pm 0,35$ & $5,03 \pm 0,52$ & 0,152 \\
\hline
\end{tabular}

${ }^{(*)}$ Giá trị thể hiện trong bảng là số trung bình \pm độ lệch chuẩn.

${ }^{(* *)} p>0,05$ không khác biệt ở múc ý nghĩa 5\%

\subsubsection{Sư dụng thuốc bảo vệ thực vật trong canh tác lúa}

Ở mỗi vụ lúa, nông dân sử dụng từ 1-2 đợt thuốc trừ cỏ và thuốc ốc, 2-4 đợt thuốc trừ sâu và 5-6 đợt thuốc phòng trị bệnh và không khác nhau nhiều giữa 02 mô hình. Nguyên nhân là do khi các hộ sản xuất lúa xung quanh sử thuốc BVTV, thuốc sầu rầy, thì các hộ thực hiện mô hình L-C-CAT buộc phải sử dụng thuốc BVTV nếu không sâu rầy sẽ tập trung về ruộng của họ. Một lý do khác là chi phí phun thuốc khá cao nên mỗi khi phun thuốc BVTV, nông dân L-C-CAT hay nông dân lúa ĐC phối trộn nhiều loại thuốc (bệnh, sâu rầy,...) để phun, vừa giảm chi phí phun thuốc vừa ngừa sâu bệnh cho lúa mặc dù một số sâu/bệnh chưa thật sự đến ngưỡng kinh tế để áp dụng phun thuốc BVTV. Bên cạnh đó, nông dân ở mô hình L-C-CAT thường chọn thuốc BVTV an toàn cho cá, loại có nhãn màu xanh lá cây và thuốc có nguồn gốc sinh học (trị rầy nâu) để sử dụng. Các loại thuốc BVTV này có nồng độ độc thấp, ít mang lại hiệu quả diệt trừ sâu bệnh tức thời nên nông dân buộc phải sử dụng nhiều lần.

Kết quả phân tích về trung bình tỷ lệ phần trăm độ độc của tất cả các loại thuốc BVTV sử dụng cho lúa trong một vụ ở nhóm nông dân L-C-CAT và nhóm lúa ĐC được trình bày ở Hình 1 . Ở mô hình L-C-CAT, loại thuốc BVTV sử dụng cho lúa có độ độc loại cẩn thận (độc nhóm IV, nhãn thuốc màu xanh lá cây) chiếm $21 \%$, độ độc loại nguy hiểm (độc nhóm III, nhãn thuốc màu xanh dương) chiếm $51 \%$ và độ độc loại độc cao (độc nhóm II, nhãn thuốc màu vàng) chiếm $28 \%$. Trong khi đó, nông dân ở mô hình lúa ĐC sử dụng thuốc BVTV có độ độc loại cẩn thận chỉ chiếm $18 \%$, độ độc loại nguy hiểm chiếm $43 \%$ và độ độc loại độc cao tăng đến $39 \%$. 


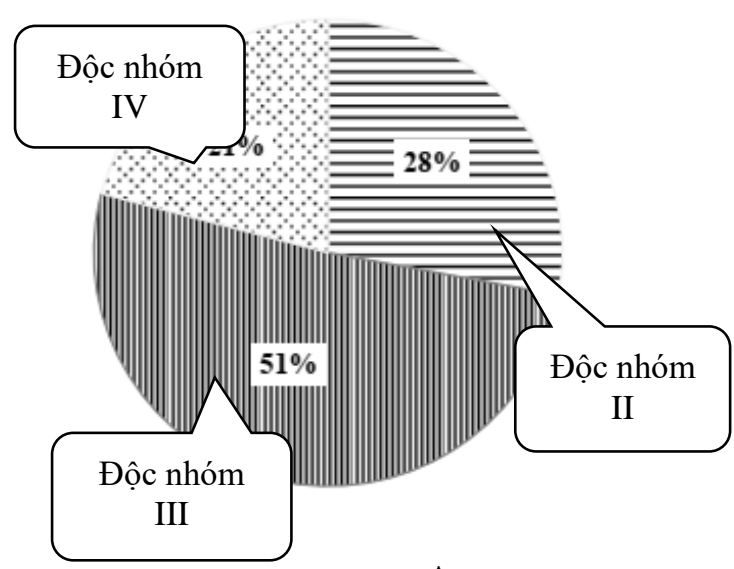

A

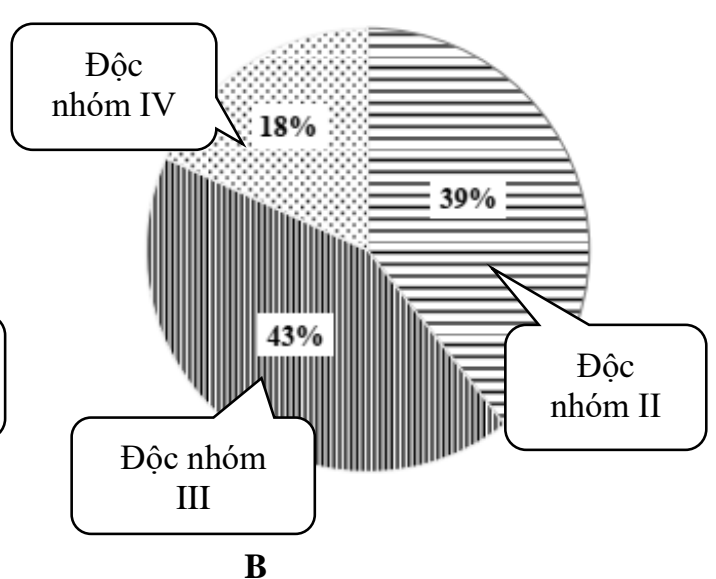

Hình 1. Trung bình tỷ lệ phần trăm độ độc của tất cả các loại thuốc BVTV sử dụng trong canh tác lúa ở một vụ trong mồ hình L-C-CAT (A) và mô hình lúa ĐC (B)

Kết quả phân tích trên cho thấy nông dân trong mô hình L-C-CAT có xu hướng hạn chế sử dụng các loại thuốc BVTV thuộc độc nhóm II để tránh ảnh hưởng bất lợi đến cá nuôi. Nông dân lúa-cá cũng có xu hướng sử dụng những loại thuốc có độ độc thấp hơn (III, IV) và cần thay đổi loại thuốc độc nhóm II ở các năm tiếp theo. Bên cạnh đó cần hạn chế bón thừa phâm đạm để lúa ít bị sâu bệnh. Ngoài ra cần tạo điều kiện cho cá vào ruộng nhiều hơn để cá phát huy tốt vai trò thiên địch trong ruộng.

\subsubsection{Năng suất lúa}

Bảng 4 cho thấy năng suất lúa thực tế tại vụ Thu Đông và Đông Xuân ở mô hình L-C-CAT cao hơn lần lượt $19 \%$ và $4 \%$ so với ở mô hình lúa $Đ C$ nhưng sự khác biệt không có ý nghĩa thống kê $(\mathrm{p}>0,05)$. Kết quả là trung bình năng suất lúa thực tế/vụ ở mô hình L-C-CAT cao hơn $12 \%$ so với ở mô hình lúa ĐC $(5,638$ so với 5,032 tấn/ha/vụ) nhưng khác biệt không có ý nghĩa thống kê. Kết quả nghiên cứu này cho thấy, việc nuôi cá trong ruộng lúa chưa có ảnh hưởng lớn đến năng suất lúa. Sự gia tăng một phần nhỏ năng suất lúa trong mô hình lúa-cá có thể là do việc bón phân cân đối và cá góp phần hạn chế sâu rầy trong ruộng lúa. Với các hoạt động canh tác tuân theo quy trình VietGAP (giống, phân, thuốc BVTV, nhật ký nông vụ, thời gian cách lý thuốc BVTV, phân tích sản phẩm lúa, đất và nước, ...) cuối vụ lúa
Hè Thu 2019, sản phẩm lúa của ND3 đạt chứng nhận VietGAP (Số 0408/GCN-TTPT, theo Quyết định số 1240/QĐ-TTPT, ngày 02/12/2019).

\subsection{Các chỉ tiêu năng suất cá}

Sau thời gian xen 2 vụ lúa -1 vụ cá $(6,9-8,3$ tháng nuôi), các chỉ tiêu về cá nuôi trong mô hình LC-CAT được trình bày ở Bảng 5 và Bảng 6 . Cá tra có tỷ lệ sống cao nhất, trung bình $77,9 \%$. Cá rô đồng có tỷ sống rất thấp, trung bình $2,1 \%(0,0-4,3 \%)$. Ở ruộng ND1 vào thời điểm thu hoạch không thu được cá rô đồng mặc dù trước đó 02 tháng có thu được mẫu cá rô đồng. Do cả 3 ruộng nuôi không có bao lưới xung quanh nên có thể cá rô đồng đã thoát ra bên ngoài vào những ngày mưa đầu mùa.

Đối với cá sặc rằn và cá trê vàng, tỷ sống sống cũng khá thấp lần lượt đạt $14 \%$ và $38,3 \%$. Các ruộng nuôi xa nhà và không có người bảo vệ thường xuyên nên có tình trạng trộm cắp cá , kết quả là tỷ lệ sống của cá trong nghiên cứu này đạt thấp. Ngoài ra, cá rô đồng, sặc rằn và cá trê vàng có tốc độ tăng trưởng thấp $(0,24-0,95 \mathrm{~g} /$ ngày) nên chậm lớn hơn so với cá tra (tốc độ tăng trưởng đạt $2-3 \mathrm{~g} /$ ngày) và vì vậy chúng dễ dàng là mồi của các loài chim cò trong môi trường tự nhiên khi mà các ruộng thí nghiệm rất gần với rừng tràm Trà Sư (huyện Tri Tôn) nơi bảo tồn nhiều chim cò.

Bảng 5. Tỷ lệ sống (TLS, \%), tốc độ tăng trưởng (TĐTT, g/ngày) của các loài cá thí nghiệm

\begin{tabular}{lrrrrrrrr}
\hline \multirow{2}{*}{ Loài cá } & \multicolumn{2}{c}{ Nông dân 1 } & \multicolumn{2}{c}{ Nông dân 2 } & \multicolumn{2}{c}{ Nông dân 3 } & \multicolumn{2}{c}{ Trung bình } \\
\cline { 2 - 10 } & TLS & TĐTT & TLS & TĐTT & TLS & TĐTT & \multicolumn{1}{c}{ TLS } & TĐTT \\
\hline Rô đồng & 0,0 & - & 4,3 & 0,95 & 2,0 & 0,83 & 2,1 & 0,89 \\
Sặc rằn & - & - & - & - & 14,1 & 0,24 & 14,1 & 0,24 \\
Trê vàng & - & - & - & - & 38,3 & 0,33 & 38,3 & 0,33 \\
Tra & 86,9 & 3,01 & 68,9 & 2,00 & - & - & 77,9 & 2,50 \\
\hline
\end{tabular}


Bảng 6. Năng suất thuần (NST, kg/ha) và năng suất thu hoạch (NSTH, kg/ha) của các loài cá tại 03 ruộng thí nghiệm

\begin{tabular}{lrrrrrrrr}
\hline \multirow{2}{*}{ Loài cá } & \multicolumn{2}{c}{ Nông dân 1 } & \multicolumn{2}{c}{ Nông dân 2 } & \multicolumn{2}{c}{ Nông dân 3 } & \multicolumn{2}{c}{ Trung bình } \\
\cline { 2 - 9 } & NST & NSTH & NST & NSTH & NST & NSTH & NST & NSTH \\
\hline Rô đồng & $-10,0$ & 0,0 & 5,9 & 23,9 & 2,3 & 12,3 & $-0,6$ & 12,7 \\
Sặc rằn & - & - & - & - & 8,6 & 22,1 & 8,6 & 22,1 \\
Trề vàng & - & - & - & - & 3,7 & 12,7 & 3,7 & 12,7 \\
Tra & $1.165,3$ & $1.238,3$ & 382,8 & 438,8 & - & - & 774,0 & 838,5 \\
Cá tự nhiên & 36,5 & 36,5 & 28,1 & 28,1 & 113,6 & 113,6 & 59,4 & 59,4 \\
\hline Tổng cộng & $1.191,8$ & $1.274,8$ & 328,6 & 490,8 & 128,2 & 160,7 & 549,5 & 642,1 \\
\hline
\end{tabular}

Tại thời điểm thu hoạch, trọng lượng trung bình của cá rô đồng đạt $188 \mathrm{~g} / \mathrm{con}$, cá tra đạt $636 \mathrm{~g} / \mathrm{con}$, đều bán được. Trong khi đó, cá sặc rằn chỉ đạt 62 $\mathrm{g} /$ con và trê vàng đạt $64 \mathrm{~g} / \mathrm{con}$, chưa đạt cỡ thương phẩm. Kết quả này cho thấy, trong điều kiện không bổ sung thức ăn, cá sặc rằn và trê vàng khó đạt cỡ thương phẩm sau thời gian nuôi của 2 vụ lúa cao sản. Đối với cá tra, với thời gian nuôi 7 - 8 tháng, trung bình năng suất thuần và thu hoạch lần lượt đạt 774,0 và $838,5 \mathrm{~kg} / \mathrm{h}$. Trong khi đó, năng suất của các loài cá nuôi khác đạt rất thấp. Ngoài cá nuôi, một số cá tự nhiên (mè vinh, rô phi, lóc, trê trắng, lòng tong, ...) cũng được thu hoạch với năng suất trung bình $59,4 \mathrm{~kg} / \mathrm{h}$. Tùy theo mức đầu tư thức ăn và loài cá nuôi, tổng năng suất cá thu hoạch ở 03 hộ thí nghiệm dao động lớn, từ $160,7 \mathrm{~kg} / \mathrm{ha}$ (không có đầu tư thức ăn) đến 1.274,8 kg/ha (có đầu tư thức ăn), trung bình đạt $642,1 \mathrm{~kg} / \mathrm{ha}$. So sánh với năng suất cá nuôi trong mô hình lúa-cá ở vùng ĐBSCL trước đây, dao động từ 326-1.058 kg/ha/7-10 tháng (Berg, 2002; Cao Quốc Nam và ctv., 2016), năng suất cá nuôi trong nghiên cứu này có phần tương đương. Tuy nhiên, ở các nghiên cứu trước ít có bổ sung thức ăn và các loài cá nuôi chủ lực là cá chép, mè hoa hay mè trắng, mè vinh, rô phi. Trong nghiên cứu này, có bổ sung thức ăn, nuôi cá tra thì năng suất nằm ở cận trên so với các nghiên cứu đây của Berg (2002) và Cao Quốc Nam và ctv. (2016). Nuôi nhóm cá đồng, không bổ sung thức ăn thì năng suất cá đạt rất thấp, do cá thất thoát nhiều và thức ăn cho nhóm cá đồng trong ruộng lúa rất hạn chế.

Tương tự như hợp phần lúa ở trên, với các hoạt động canh tác lúa và nuôi cá tuân theo quy trình VietGAP (phần cá: sử dụng cá giống, thức ăn, men vi sinh, vitamin, sử dụng thuốc kháng sinh nằm trong danh mục cho phép, nhật ký nông vụ, phân tích sản phẩm cá, đất và nước, ,...), sản phẩm cá của ND3 đạt chứng nhận VietGAP (Số 0416/GCNTTPT, theo Quyết định số 1255/QĐ-TTPT, ngày 03/12/2019).

\subsection{Hợp phần cây ăn trái}

Sau thời gian trồng 2-3 năm, cây ăn trái phát triển khá tốt ở mô hình L-C-CAT, riêng cây bưởi thường bị sâu vẽ bùa, vàng lá gân xanh, bệnh thán thư,... Khoảng $20 \%$ số lượng cây bưởi kém phát triển được thay mới bằng cây khác. Từ tháng 2 đến tháng 9 năm 2019, 03 hộ đã có thu hoạch cây ăn trái (Bảng 7). Các cây ăn trái khác như bưởi, cam đã cho trái chiến ở cả 3 hộ nhưng nông dân đã loại bỏ, chờ thu hoạch đợt sau. Theo nông dân, hợp phần cây ăn trái có khả năng giúp nông dân gắn kết hoạt động nông nghiệp với du lịch của địa phương, được người dân kỳ vọng và trong đợi nhiều.

Bảng 7. Lượng trái cây (kg/ha/mô hình) thu hoạch tại các hộ thực hiện thí nghiệm ${ }^{(*)}$

\begin{tabular}{lrrrlrrr}
\hline Loại & Nông dân 1 & Nông dân 2 & Nông dân 3 & \multicolumn{3}{c}{ Loại Nông dân 1 Nông dân 2 Nông dân 3 } \\
\hline Xoài & - & 1.828 & - & Mãng câu & 51 & - & - \\
Mít & 2.353 & - & 185 & Chanh & - & 457 & - \\
Cà na & 358 & - & - & Ối & 128 & - & - \\
\hline
\end{tabular}

(*) Diện tích bò̀ trồng cây ăn trái của nông dân 1, nông dân 2 và nông dân 3 là̀n luợt là 0,15 ha, 0,27 ha và 0,32 ha

\subsection{Hiệu quả tài chính của các mô hình canh tác}

\subsubsection{Chi phí và lợi nhuận của hợp phần lúa trong 02 mô hìn canh tác}

Tổng chi phí, tổng thu và lợi nhuận từ hợp phần lúa khác biệt không ý nghĩa thống kề $(\mathrm{p}>0,05)$ giữa hai mô hình L-C-CAT và lúa ĐC ở vụ Thu Đông 2018 và Đông Xuân 2018 - 2019 (Bảng 8).

Khi xét về tổng 2 vụ lúa/1vụ cá, tổng chi phí sản xuất lúa trên cùng diện tích trồng lúa ở mô hình LC-CAT là 39,1 triệu đồng/ha ruộng/2 vụ, thấp hơn nhưng khác biệt không ý nghĩa so với ở mô hình lúa ĐC (40,7 triệu đồng/ha ruộng/2 vụ). Trong khi đó 
tổng thu từ lúa cao hơn ở mô hình L-C-CAT so với mô hình lúa $Đ C$, nếu xét ở mức ý nghĩa $\alpha \leq 10 \%$ (Bảng 8). Mặc dù không khác biệt ( $\mathrm{p}>0,05)$, năng suất lúa ở mô hình L-C-CAT cao hơn $12 \%$ so với mô hình lúa $\mathrm{C}$ (Bảng 4). Thêm vào đó, trung bình giá bán lúa ở mô hình L-C-CAT là 5,267 đồng/kg cao hơn so với giá bán lúa ở mô hình lúa ĐC là 5,117 đồng $/ \mathrm{kg}$. Kết quả là mô hình L-C-CAT đạt lợi nhuận 20,6 triệu đồng/ha ruộng/2 vụ, cao hơn 53,7\% ở mức ý nghĩa $\alpha=5 \%$ so với mô hình lúa ĐC $(13,4$ triệu đồng/ha ruộng/2 vụ). Tuy nhiên, tỷ suất lợi nhuận trên chi phí hay trên tổng thu của 02 mô hình khác biệt không ý nghĩa thống kê.
Bảng 8. Chi phí, tổng thu và lọii nhuận (triệu đồng/ha ruộng) của hợp phần lúa ở các mô hình ${ }^{(*)}$

\begin{tabular}{lrrr}
\hline Chỉ tiêu & L-C-CAT & Lúa ĐC & $\mathbf{p}^{(* *)}$ \\
\hline TĐ 2018 & & & \\
\hline Chi phí & $19,6 \pm 2,0^{\mathrm{a}}$ & $19,6 \pm 3,1^{\mathrm{a}}$ & 0,998 \\
Tổng thu & $33,4 \pm 3,6^{\mathrm{a}}$ & $28,7 \pm 2,5^{\mathrm{a}}$ & 0,141 \\
Lợi nhuận & $13,8 \pm 1,7^{\mathrm{a}}$ & $9,1 \pm 5,1^{\mathrm{a}}$ & 0,206 \\
\hline ĐX 2018-2019 & & & \\
\hline Chi phí & $19,6 \pm 3,0^{\mathrm{a}}$ & $18,8 \pm 0,0^{\mathrm{a}}$ & 0,769 \\
Tổng thu & $26,7 \pm 1,2^{\mathrm{a}}$ & $24,8 \pm 1,1^{\mathrm{a}}$ & 0,244 \\
Lợi nhuận & $7,1 \pm 4,2^{\mathrm{a}}$ & $6,0 \pm 1,1^{\mathrm{a}}$ & 0,774 \\
\hline HT 2019 & & & \\
\hline Chi phí & 19,4 & 25,7 & - \\
Tổng thu & 25,7 & 26,7 & - \\
Lợi nhuận & 6,3 & 1,0 & - \\
\hline Tồng 2 vụ lúa & & & \\
\hline Chi phí & $39,1 \pm 4,1^{\mathrm{a}}$ & $40,7 \pm 7,0^{\mathrm{a}}$ & 0,756 \\
Tô̂ng thu & $59,8 \pm 2,8^{\mathrm{a}}$ & $54,1 \pm 2,4^{\mathrm{a}}$ & 0,058 \\
Lợi nhuận & $20,6 \pm 1,3^{\mathrm{a}}$ & $13,4 \pm 8,1^{\mathrm{b}}$ & 0,050 \\
Lợi nhuận/Chi phí & $0,53 \pm 0,09^{\mathrm{a}}$ & $0,36 \pm 0,23^{\mathrm{a}}$ & 0,278 \\
$\begin{array}{l}\text { Lợi nhuận/Tổng } \\
\text { thu }\end{array}$ & $0,35 \pm 0,04^{\mathrm{a}}$ & $0,25 \pm 0,14^{\mathrm{a}}$ & 0,367 \\
\hline
\end{tabular}

${ }^{(*)}$ Giá trị thể hiện trong bảng là số trung bình \pm độ lệch chuẩn. Trong cùng một hàng các giá trị trung bình theo sau cùng mẫu tụ thì không khác biệt ở mức ý nghĩa $\alpha>5 \%$,

${ }^{(* *)} p>0,05$ không khác biệt ở mức ý nghĩa 5\%; $p \leq 0,05$ khác biệt ở mức ý nghĩa 5\%

Theo Berg (2002), nếu áp dụng kỹ thuật canh tác IPM trên lúa và có nuôi cá trong ruộng thì chi phí sản xuất lúa trong mô hình kết hợp lúa-cá thấp hơn so với mô hình lúa ĐC do giảm chi phí thuốc BVTV. Trong nghiên cứu này không cho kết quả tương tự, chi phí sản xuất lúa tương tự giữa hai mô hình. Nguyên nhân là do ở mô hình L-C-CAT nông dân đa phần sử dụng các loại nông dược có độ độc thấp (nhãn màu xanh lá cây và xanh dương, Hình 1 ), sinh học, giá mua cao nhưng hiệu quả kém hơn so với các loại thuốc có độ độc cao hơn (nhãn màu xanh dương và màu vàng) nên nông dân lúa-cá phải tăng số lần hay lượng sử dụng, dẫn đến làm tăng nhẹ chi phí thuốc BVTV ở mô hình L-C-CAT. Từ các kết quả trên cho thấy nếu giá bán lúa từ mô hình $\mathrm{L}-\mathrm{C}$ CAT tăng lên (xứng với đạt chuẩn VietGAP) thì sẽ góp phần làm tăng thêm lợi nhuận của hợp phần lúa trong mô hình L-C-CAT và sự khác biệt về lợi nhuận và tỷ suất lợi nhuận giữa 02 mô hình sẽ cao hơn.

\subsubsection{Chi phí và lợi nhuận của hợp phần cá trong mô hìn $L-C-C A T$}

Tổng chi phí nuôi cá dao động lớn giữa 3 hộ, từ 9,22 - 26,64 triệu đồng/ha mương ruộng/vụ cá (Bảng 9), cao nhất là hộ ND1 do có đầu tư nhiều thức ăn, tiếp đến là hộ ND2 (đầu tư thức ăn ít hơn) và thấp nhất ở hộ ND3 (không có đầu tư thức ăn). Tổng thu từ cá cũng có sự chênh lệch, cao nhất là hộ ND1 và thấp nhất là hộ ND3. Sau khi trừ chi phí, hộ ND1 hòa vốn, hộ ND2 và ND3 lần lượt lỗ 0,8 và 6,1 triệu đổng/ha mương ruộng. Hợp phần cá nuôi không có lời là do hai nguyên nhân sau. Thứ nhất, tỷ lệ sống của các loài cá rô đồng $(2,1 \%)$, sặc rằn $(14,1 \%)$ và trê vàng $(38,3 \%)$ là quá thấp (Bảng 5$)$. Thứ hai, giá bán cá tra của 2 hộ thí nghiệm ở thời điểm tháng 4 năm 2019 rất thấp $(20.000$ đồng $/ \mathrm{kg})$. Theo Cục Thống kê tỉnh An Giang (2019), do xuất khẩu cá tra vào các thị trường lớn (Mỹ, Trung Quốc) bị chậm lại đồng thời lượng tồn kho nguyên liệu còn nhiều, các doanh nghiệp hạn chế mua làm giá cá tra trên thị trường giảm. Giữa tháng $3 / 2019$, giá cá tra nguyên liệu giảm còn 24 - 24,5 ngàn đồng/kg (loại 0,8-0,9 $\mathrm{kg} / \mathrm{con}$ ), các mức giá này giảm từ $5-5,5$ ngàn đồng $/ \mathrm{kg}$ so tháng $01 / 2019$. Do vậy với giá bán cá tra tại địa bàn nghiên cứu là 20.000 đồng/kg (số lượng ít, bán cho người bán lẻ) thì người nuôi cá ruộng không có lãi.

Theo nghiên cứu ở năm 2014, lợi nhuận từ cá trong mô hình lúa-cá ở thành phố Cần Thơ, tỉnh Hậu Giang, tỉnh Vĩnh Long và Đồng Tháp dao động từ 3,49 đến 9,98 triệu đồng/ha (Cao Quốc Nam và $c t v$., 2016). Điều này cho thấy nuôi cá trong ruộng lúa ở xã Ô Long Vĩ chưa mang lại hiệu quả. Muốn tăng lợi nhuận của hợp phần cá người nuôi cần phải điều chỉnh lại một số kỹ thuật nuôi để hạn chế cá thất thoát, gia tăng tỷ lệ sống của nhóm cá đồng bằng cách thường xuyên thăm ruộng, ngăn chặn đường cá thất thoát, phòng nạn trộm cắp cá (nạn xiệp điện, chim cò săn cá,...). Bên cạnh đó cần hạn chế tình trạng rửa phèn (tưới cây) từ bờ trồng cây ăn trái trực tiếp xuống mương nuôi cá. Hơn nữa, cần tìm nơi tiểu thụ cá đạt tiêu chuẩn VietGAP, để bán cá có giá cao hơn. 
Bảng 9. Chi phí, tổng thu và lợi nhuận của hợp phần cá (triệu đồng/ha mương ruộng) và hợp phần cây ăn trái (CAT, triệu đồng/ha mô hình) trong mô hình L-C-CAT

\begin{tabular}{|c|c|c|c|c|c|c|c|c|}
\hline \multirow{2}{*}{ Chỉ tiêu } & \multicolumn{2}{|c|}{ Nông dân 1} & \multicolumn{2}{|c|}{ Nông dân 2} & \multicolumn{2}{|c|}{ Nông dân 3} & \multicolumn{2}{|c|}{ Trung bìnhh } \\
\hline & Cá & CAT & Cá & CAT & Cá & CAT & Cá & CAT \\
\hline Tồng chi & 26,64 & 15,05 & 11,34 & 17,144 & 9,22 & 22,400 & 15,731 & 18,200 \\
\hline Chi phí cố định & 0,43 & 3,47 & 0,28 & 2,86 & 0,33 & 4,75 & 0,345 & 3,69 \\
\hline Lên bờ & & 0,73 & & 0,81 & & 0,96 & & 0,83 \\
\hline Cây giống & & 0,99 & & 0,28 & & 2,42 & & 1,23 \\
\hline Dụng cụ & & 1,75 & & 1,78 & & 1,37 & & 1,63 \\
\hline Chi phí biến đổi & 26,20 & 11,59 & 11,06 & 14,299 & 8,90 & 17,650 & 15,386 & 14,514 \\
\hline Cá giống & 3,18 & & 2,95 & & 3,32 & & 3,148 & \\
\hline Thức ăn, men vi sinh, & 17,94 & 3,56 & 3,82 & 3,929 & 0,00 & 1,944 & 7,256 & 2,933 \\
\hline Vôi bột, dây thuốc cá, thuốc BVTV & 0,93 & 1,74 & 0,55 & 2,744 & 1,34 & 6,818 & 0,941 & 3,772 \\
\hline Nhiên liệu & 0,40 & 0,50 & 0,50 & 1,199 & 0,50 & 1,355 & 0,467 & 1,016 \\
\hline Lao động & 3,76 & 5,79 & 3,24 & 7,072 & 3,74 & 7,553 & 3,580 & 6,803 \\
\hline Tổng thu & 26,64 & 79,41 & 10,54 & 23,222 & 3,11 & 3,700 & 13,427 & 35,444 \\
\hline Cá nuôi & 24,77 & & 9,49 & & 1,25 & & 11,835 & \\
\hline Cá tự nhiên & 1,87 & & 1,04 & & 1,86 & & 1,592 & \\
\hline Lợi nhuận & 0,01 & 64,36 & $-0,80$ & 6,088 & $-6,12$ & -18.70 & $-2,304$ & 17,255 \\
\hline
\end{tabular}

\subsubsection{Chi phí và lợi nhuận của hợp phần câyăn trái trong mô hình lúa-cá- cây ăn trái}

Chi phí đầu tư cây ăn trái ở 3 hộ dao động từ 15,05 - 22,40 triệu đồng/ha/mô hình, chủ yếu là chi phí phân, thuốc BVTV và lao động (Bảng 9). Mặc dù chi phí đầu tư cao, nhưng do trồng chủ yếu bưởi và cam (3 - 4 năm mới cho trái) nên đến năm 2019 hộ ND3 chỉ có tổng thu từ 25 cây mít trồng trước. Ở hộ ND1, có thu hoạch từ nhiều loại cây: 60 cây mít trồng trước đó (2016), cà na, ổi và mãn cầu nên có tổng thu nhiều nhất (79,41 triệu đồng/ha). Hộ ND2 cũng có nguồn thu từ cây chanh và cây xoài. Do chi phí đầu tư thấp nhưng được mùa và được giá (mít) nên lợi nhuận của hợp phần cây ăn trái ở hộ ND1 cao nhất (64,36 triệu đồng/ha), kế đến là hộ ND2 (6,08 triệu đồng/ha). Ở hộ ND3, chưa có thu hoạch cây ăn trái nhiều nên lợi nhuận âm, và lợi nhuận sẽ thay đổi ở 1 - 2 năm tiếp theo khi có thu hoạch.

\subsubsection{Chi phí, tổng thu và lợi nhuận các mô hình canh tác}

Bảng 10 trình bày hiệu quả tài chính toàn phần của mô hình L-C-CAT (xen canh 2 vụ lúa, 1 vụ cá và 1 vụ cây ăn trái) và lúa ĐC (2 vụ lúa). Do có đầu tư và vận hành thêm hợp phần cá và cây ăn trái nên tổng chi phí đầu tư của mô hình L-C-CAT là 54,77 triệu đồng/ha cao hơn có ý nghĩa so với mô hình lúa ĐC là 41,71 triệu đồng/ha. Tổng tổng thu từ mô hình L-C-CAT là 82,90 triệu đồng/ha và tổng thu từ mô hình lúa ĐC là 54,14 triệu đồng/ha. Kết quả là tổng lợi nhuận của mô hình L-C-CAT và lúa ĐC lần lượt là 28,13 và 13,44 triệu đồng/ha. Tổng thu, lợi nhuận và thu nhập từ mô hình $\mathrm{L}-\mathrm{C}-\mathrm{CAT}$ lần lượt cao hơn khoảng 53\%, 209\% và $216 \%$ với mô hình lúa ĐC. Tuy nhiên những sự khác biệt này không có ý nghĩa thống kê $(p>0,05)$. Nguyên nhân là do tổng thu và lợi nhuận từ hợp phần cây ăn trái ở hộ ND3 không nhiều so với hai hộ còn lại, làm tăng sự biến động số liệu trong nhóm nông dân L-C-CAT, dẫn đến kết quả không khác biệt có ý nghĩa thống kê giữa 02 mô hình. Do chi phí đầu tư ở mô hình L-C-CAT cao nên tỷ suất lợi nhuận trên chi phí hay lợi nhuận trên tổng thu ở mô hình L-C-CAT có xu hướng thấp hơn so với ở mô hình lúa ĐC.

Tỷ suất của lợi nhuận biên tế (MRR) được trình bày ở Bảng 10 , cho thấy giá trị MRR nông dân có thể nhận được là 104,5\% khi thay đổi từ mô hình lúa ĐC (MH2) sang mô hình L-C-CAT (MH1). Điều này có nghĩa là khi nông dân thay đổi từ mô hình lúa ĐC sang mô hình L-C-CAT trong một đầu tư là 100.000 đồng, nông dân sẽ thu hồi lại vốn và lời là 204.500 đồng. Như vậy, mô hình L-C-CAT có thể khuyến cáo cho nông dân.

Khi phân tích và đánh giá hiệu quả tài chính từng phần của mô hình L-C-CAT và lúa ĐC qua phương pháp PBA cho thấy phần chênh lệch III > 0 (Bảng 11), khẳng định mô hình L-C-CAT đạt hiệu quả về thay thế kỹ thuật canh tác so với mô hình lúa ĐC.

Theo Berg (2002), tại tỉnh Tiền Giang và thành phố Cần Thơ, lợi nhuận từ mô hình xen canh 2-3 lúa và 1 cá có kết hợp với kỹ thuật canh tác IPM đạt lợi nhuận 19,52 triệu đồng/ha, cao hơn có ý nghĩa $19,17 \%$ \% so với ở mô hình độc canh 2-3 vụ lúa/năm (15,76 triệu động/ha), chủ yếu là do giảm chi phí sản xuất và tăng năng suất lúa và cá. Tương tự theo Lê 
Thị Thanh Nga \& Lê Xuân Sinh (2008), mô hình xen canh 2 lúa và 1 cá (nuôi qua mùa lũ) ở tỉnh Hậu
Giang có lợi nhuận 25,96 triệu đồng/ha, cao hơn có ý nghĩa 16,26\% so với mô hình lúa ĐC 3 vụ/năm.

Bảng 10. Chi phí, tổng thu và lọi nhuận (triệu đồng/ha/mô hình) của các mô hình canh tác

\begin{tabular}{lrrr}
\hline Chỉ tiêu & L-C-CAT (MH1) & Lúa ĐC (MH2) $^{\text {(M) }}$ & p $^{(* *)}$ \\
\hline Chi phí & $54,77 \pm 4,12^{\mathrm{a}}$ & $40,71 \pm 7,01^{\mathrm{b}}$ & 0,040 \\
\hline Lúa & $24,10 \pm 4,89$ & $40,71 \pm 7,01$ & \\
Cá & $12,47 \pm 7,85$ & & \\
Cây ăn trái & $18,20 \pm 3,79$ & & \\
\hline Tổng thu & $82,90 \pm 49,65^{\mathrm{a}}$ & $54,14 \pm 2,40^{\mathrm{a}}$ & 0,373 \\
\hline Lúa & $36,72 \pm 5,74$ & $54,14 \pm 2,40$ & \\
Cá & $10,73 \pm 9,77$ & & \\
Cây ăn trái & $35,45 \pm 39,31$ & & \\
Lợi nhuận & $28,13 \pm 45,85^{\mathrm{a}}$ & $13,44 \pm 8,06^{\mathrm{a}}$ & 0,614 \\
\hline Lúa & $12,63 \pm 1,43$ & $13,44 \pm 8,06$ & \\
Cá & $-1,74 \pm 2,49$ & & \\
Cây ăn trái & $17,25 \pm 42,64$ & & \\
Thu nhập & $36,21 \pm 48,65^{\mathrm{a}}$ & & \\
\hline Lợi nhuận/chi phí & $0,48 \pm 0,80^{\mathrm{a}}$ & 0,530 \\
Lợi nhuận/tổng thu & $0,17 \pm 0,45^{\mathrm{a}}$ & $0,36 \pm 0,23^{\mathrm{a}}$ & 0,816 \\
MRR (MH2 - MH1) & $104,5 \%$ & $0,25 \pm 0,14^{\mathrm{a}}$ & 0,778 \\
\hline
\end{tabular}

${ }^{(*)}$ Giá trị thể hiện trong bảng là số trung bình \pm độ lệch chuẩn. Trong cùng một hàng các giá trị trung bình theo sau cùng mẫu tụ thì không khác biệt ở mức ý nghĩa $\alpha>5 \%$,

${ }^{(* *)} p>0,05$ không khác biệt ở mức ý nghĩa 5\%; $p \leq 0,05$ khác biệt ở múc ý nghĩa 5\%.

\section{Bảng 11. Kết quả phân tích tài chính từng phần từ mô hình L-C-CAT và lúa $Đ C$}

\begin{tabular}{lr}
\hline I: Phần tăng (triệu đồng/ha) & $\mathbf{1 2 3 , 6 0}$ \\
$\mathrm{I}_{1}$ : Tồng thu tăng [tổng thu từ mô hình L-C-CAT (triệu đồng/ha)] & 82,90 \\
$\mathrm{I}_{2}$ : Chi phí giảm [chi phí sản xuất trong mô hình lúa ĐC (triệu đồng/ha)] & 40,71 \\
\hline II: Phần giảm & $\mathbf{1 0 8 , 9 1}$ \\
\hline $\mathrm{II}_{1}$ : Tống thu giảm [tổng thu từ mô hình lúa ĐC (triệu đồng/ha)] & 54,14 \\
$\mathrm{II}_{2}$ : Chi phí tăng [chi phí sản xuất trong mô hình L-C-CAT (triệu đồng/ha)] & 54,77 \\
Phần III: Chênh lệch (III = I - II) & $\mathbf{1 4 , 6 9}$ \\
\hline
\end{tabular}

Trong nghiên cứu này, lợi nhuận ở mô hình LC-CAT cũng có xu hướng cao hơn so với mô hình lúa ĐC $(209 \%)$ là do tăng năng suất lúa trên cùng đơn diện tích canh tác lúa (Bảng 4) do đó làm tăng lợi nhuận từ lúa (Bảng 8). Bên cạnh đó hợp phần cây ăn trái đóng góp rất nhiều vào lợi nhuận của mô hình L-C-CAT (Bảng 10). Trong khi đó, hợp phần cá nuôi chưa đem lại lợi nhuận. Một lần nữa có thể thấy để tăng lợi nhuận của mô hình L-C-CAT cần phải cải tiến hợp phần cá nuôi do hiện tại vẫn còn nhiều hạn chế trong kỹ thuật canh tác và quản lí. Khi năng suất cá nuôi được tăng cao hơn, đặc biệt là nhóm cá có khả năng kiểm soát sâu rầy thì sẽ góp phần hạn chế hơn chi phí thuốc sâu, thuốc bệnh. Bên cạnh đó, tiêu thụ lúa và cá đã đạt chuẩn VietGAP, bán giá cao hơn, mang lại lợi nhuận cao hơn cho mô hình L-CCAT để tăng tính hấp dẫn và chấp nhận mô hình $\mathrm{L}$ C-CAT đối với người dân là hết sức cần thiết để hướng đến sản xuất lúa-cá theo hướng an toàn và bền vững.

\section{KẾT LUẬN VÀ ĐỀ XUẤT}

Kết quả thử nghiệm mô hình L-C-CAT tại xã Ô Long Vĩ, huyện Châu Phú, tỉnh An Giang cho kết quả khả quan, làm đa dạng hóa sản phẩm nông nghiệp, hướng đến canh tác lúa đạt theo tiêu chuẩn VietGAP. Bằng hình thức sản xuất lúa-cá kết hợp, nông dân đã giảm lượng lúa giống gieo sạ, phân đạm, sử dụng thuốc BVTV có độ độc thấp nhưng năng suất lúa có tăng nhưng khác biệt không ý nghĩa thống kê. Lợi nhuận từ hợp phần lúa tăng $53,7 \%$ so với sản xuất lúa độc canh trên cùng diện tích canh tác lúa. Mặc dù hợp phần cá nuôi trong mô hình LC-CAT chưa đạt hiệu quả tài chính nhưng sản phẩm một số loài cá nuôi đã đạt tiêu chuẩn VietGAP. Hợp phần cây ăn trái có kết quả nhiều triển vọng, có lợi 
nhuận. Trên cơ sở kết quả phân tích tỷ suất của lợi nhuận biên tế (MRR) mô hình L-C-CAT đạt hiệu quả tài chính ở mức chấp nhận, có thể khuyến cáo đến nông dân. Nghiên cứu cũng khuyến cáo cần tiếp tục cải tiến mô hình L-C-CAT bằng cách nâng cao năng suất cá nuôi, phát huy hơn vai trò thiên địch của cá đối với sâu hại trong ruộng lúa cũng như nâng giá bán lúa và cá đã đạt chứng nhận VietGAP.

\section{LỜI CẢM TẠ}

Nghiên cứu này được thực hiện với kinh phí của Sở Khoa học và Công nghệ tỉnh An Giang. Chúng tôi chân thành cảm ơn bà con nông dân và tập thể cán bộ xã Ô Long Vĩ, huyện Châu Phú, tỉnh An Giang đã giúp chúng tôi trong quá trình nghiên cứu.

\section{TÀI LIỆU THAM KHẢO}

Berg, H. (2002). Rice monoculture and integrated rice-fish farming in the Mekong Delta, Vietnameconomic and ecological considerations. Ecological Economics 41, 95-107.

Billy, V.L., Dale, M.J., \& James, C.H. (1991). Using the partial budget to analyze farm change. Fasst sheet 547, University of Mariland. https://www.arec.umd.edu/sites/arec.umd.edu/fil es/files/documents/Archive/Using\%20the\%20Par tial\%20Budget_0.pdf.

Cao Quốc Nam, Nguyễn Văn Nhiều Em \& Phạm Thị Tố Anh. (2016). Đánh giá hiện trạng kỹ thuật và tài chính của mô hình nuôi cá trong ruộng lúa ở Đồng bằng sông Cửu Long. Tạp chí Khoa học Trường Đại học Cần Thơ. Phần B: Nông nghiệp, Thủy sản và Công nghệ Sinh học, 47, 24-37.

Cục Thống kê tỉnh An Giang. (2019). Báo cáo tình hình kinh tế - xã hội Quý I năm 2019 (Số:165/BC-CTK).

Garbach, K., Vu, T. T. A., Buchori, D., Ravanera, R., Boualaphanh, C., Ketelaar, J. W., \& Gemmill-Herren, B. (2014). The Multiple Goods and Services of Asian Rice Production Systems. FAO. http://www.fao.org/3/a-i3878e.pdf

Halwart, M., \& Gupta, M.V. (Eds.). (2004). Culture of fish in rice fields. FAO and The World Fish Center.

Lê Thị Thanh Nga \& Lê Xuân Sinh. (2008). Khía cạnh kỹ thuật và hiệu quả kinh tế của mô hình canh tác lúa- cá và lúa độc canh ở vùng dự án thủy lợi Ô Môn - Xà No. Tạp chí Khoa học Trường Đại học Cần Thơ, 2, 176-187.
Lê Văn Dang, Ngô Ngọc Hưng \& Lâm Ngọc Phương. (2018). Hấp thu $\mathrm{N}, \mathrm{P}, \mathrm{K}$ và nhu cầu phân bón của lúa trồng trên đất phèn ở đồng bằng sông Cửu Long. Tạp chí Nông nghiệp và Phát triển Nông thôn, 2, 11-19.

Nguyễn Duy Cần, Johan, R., \& Vromant, N. (2009). PTD - Phát triển kỹ thuật có sự tham gia. NXB Nông nghiệp.

Nguyễn Ngọc Đệ. (2009). Giáo trình cây lúa. Nhà xuất bản Đại học Quốc gia Thành phố Hồ Chí Minh.

Nguyễn Quang Tuyến. (2013). Hệ thống hóa các mô hình sản xuất lúa vùng sinh thái ngọt Đồng bằng sông Cửu Long. Tạp chí Khoa học Trường Đại học Cần Thơ. Phần B: Nông nghiệp, Thủy sản và Công nghệ Sinh học. 29, 60-69.

Phạm Văn Toàn. (2013). Thực trạng sử dụng thuốc bảo vệ thực vật và một số giải pháp giảm thiểu việc sử dụng thuốc không hợp lý trong sản xuất lúa ở Đồng bằng sông Cửu Long. Tạp chí Khoa học Trường Đại học Cần Thơ, 28, 47-53.

Robert, T. (2018). Partial budgeting: A tool to analyze farm busness changes, IOWA State University.

https://www.extension.iastate.edu/agdm/wholefa $\mathrm{rm} / \mathrm{html} / \mathrm{c} 1-$

50.html\#: :text=A\%20partial\%20budget $\% 20$ hel ps $\% 20$ farm,business $\% 20$ that $\% 20$ are $\% 20$ left $\% 20$ unchanged

Sở Nông nghiệp và Phát triển nông thôn tỉnh An Giang. (2014). Báo cáo tổng hợp quy hoạch tổng thể phát triển ngành nông nghiệp và phát triển nông thôn tỉnh An Giang đến năm 2020, định hướng đến năm 2030.

The International Maize and Wheat Improvement Center. (1988). From Agronomic data to farmer recommendations: An economics training manual. Completely revised edition. https://repository.cimmyt.org/xmlui/bitstream/ha ndle/10883/859/25152.pdf

United Nations Environment Program. (2005). Integrated assessment of the impact of trade liberalization: A country study on the Vietnam rice sector.

https://wedocs.unep.org/bitstream/handle/20.500. $11822 / 9284 /-$

Integrated $\% 20$ Assessment $\% 20$ of $\% 20$ Trade $\% 20$ Liberalization\%20in\%20the\%20Rice\%20Sector $\% 20$ A $\% 20$ Country $\% 20$ Case $\% 20$ Study $\% 20$ in $\% 2$ 0Vietnam2005Vietnam.pdf? sequence $=2 \&$ isAllowed $=y$ 